\title{
Expression of angiopoietin-like 4 in human gastric cancer: ANGPTL4 promotes venous invasion
}

\author{
TOSHIYUKI NAKAYAMA ${ }^{1}$, HIROSHI HIRAKAWA ${ }^{2}$, KENICHIRO SHIBATA $^{2,3}$, KUNIKO ABE $^{1}$, \\ TAKESHI NAGAYASU ${ }^{3}$ and TAKASHI TAGUCHI ${ }^{1}$ \\ Departments of ${ }^{1}$ Pathology, ${ }^{2}$ Tumor and Diagnostic Pathology, and ${ }^{3}$ Surgical Oncology, \\ Nagasaki University Graduate School of Biomedical Sciences, Nagasaki 852-8523, Japan
}

Received April 30, 2010; Accepted June 15, 2010

DOI: 10.3892/or_00000897

\begin{abstract}
There is strong evidence that the angiopoietin family is involved in the regulation of tumour progression, cellular growth and differentiation. Recently, it has been reported that angiopoietin-like 4 (ANGPTL4) in cancer cell promotes the metastatic process by increasing vascular permeability. To elucidate ANGPTL4 expression and its association with clinicopathological factors and prognosis in human gastric adenocarcinomas, we examined 103 cases of surgicallyresected human gastric adenocarcinoma by immunohistochemistry. Among 103 cases of adenocarcinoma, 38 cases (36.9\%) showed positive staining in the cytoplasm of the carcinoma cells for ANGPTL4. Histologically, papillary and mucinous adenocarcinomas showed relatively high expression of ANGPTL4 (60 and 60\%, respectively). The expression of ANGPTL4 was correlated with the depth of tumour invasion $(\mathrm{p}<0.005)$, lymph node metastasis $(\mathrm{p}<0.001)$, venous invasion $(\mathrm{p}<0.00005)$ and TNM stage $(\mathrm{p}<0.001)$ in the total carcinoma. In univariate survival analysis, ANGPTL4 expression was not associated with the overall survival. RT-PCR or Western blot analysis showed the expression of mRNA or protein of ANGPTL4 in all four surgically-resected samples and all four cell lines of human gastric adenocarcinoma. ANGPTL4 expression was correlated with several clinicopathological factors, especially venous invasion. These findings suggest that the ANGPTL4 is one of the factors involved in the progression of human gastric cancer.
\end{abstract}

\section{Introduction}

Gastric cancer is one of the most common cancer types in the world today, in spite of the fact that its incidence has shown a

Correspondence to: Dr Toshiyuki Nakayama, Department of Pathology, Nagasaki University Graduate School of Biomedical Sciences, 1-12-4 Sakamoto, Nagasaki 852-8523, Japan

E-mail: toshi-n@nagasaki-u.ac.jp

Key words: Angiopoietin-like 4, human gastric cancer, venous invasion, immunohistochemistry gradual decline in many countries (1). The occurrence and progression of cancer are considered to be a series of genetic events affecting the structure and/or expression of a number of oncogenes, tumour suppressors and growth factors $(2,3)$. The deep invasive carcinomas, such as gastric cancer, have higher rates of lymph duct and venous invasions and lymph node metastasis (4). However, the mechanisms of invasion and metastasis of gastric carcinoma are not fully understood.

The molecular mechanisms in tumour progression, local invasion and the formation of tumour metastases represent a major challenge in cancer research. Metastasis of tumour cells is the primary cause of death in patients with cancer (5). To metastasize, tumour cells undergo a multistep progression through a series of sequential and selective events (6). The metastatic process consists of tumour cell detachment, local invasion, motility, angiogenesis, vessel invasion, survival in the circulation, adhesion to endothelial cells, extravasation and regrowth in different organs (7). In each step, causative molecules have been identified; these include cell-adhesion molecules, various growth factors, matrix degradation enzymes and motility factors, of which most of these can be regarded as prognostic factors (7).

There is strong evidence that the angiopoietin family is involved in the regulation of tumour progression, cellular growth and differentiation (8-10). Angiopoietin-like 4 (ANGPTL4) is a member of the family of angiopoietins and is known as hepatic fibrinogen/angiopoietin-related protein (HEARP) (11), peroxisome proliferator-activated receptor- $\gamma$ $(\operatorname{PPAR} \gamma)$ angiopoietin-related gene (PGAR) (12) or fastinginduced adipose factor (FIAF) (13). Similar to angiopoietins and other angiopoietin-like proteins, ANGPTL4 contains an amino-terminal coiled-coil domain and a carboxyl-terminal fibrinogen-like domain (14). Oligomerized ANGPTL4 undergoes proteolytic processing to release its carboxyl fibrinogen-like domain, which circulates as a monomer (14).

ANGPTL4 is a circulating plasma protein, expressed in the liver, adipose tissue and placenta, as well as in ischemic tissue $(12,13)$, and induces a strong proangiogenic response, independently of vascular endothelial growth factor (15). ANGPTL4 is known as a gene with hypoxia-induced expression in endothelial cells. This protein is up-regulated by fasting and peroxisome proliferator-activated receptor agonists, associates with lipoproteins (12), and is involved in regulating glucose homeostasis, insulin sensitivity and lipid metabolism 
through its capacity to inhibit lipoprotein lipase (12,16-18). However, the role of ANGPTL4 is not clarified in cancer biology, although the role of ANGPTL4 has been well characterized in ischemic conditions and lipid metabolism.

Recently, it has been reported that the induction of ANGPTL4 by TGF- $\beta$ primes breast cancer for lung metastasis (19). Tumour cell-derived ANGPTL4 disrupts vascular endothelial cell-cell junctions, increases the permeability of lung capillaries, and facilitates the trans-endothelial passage of cancer cells. Secretion of ANGPTL4 enables tumour cells to extravasate into other tissue and to seed micrometastases. However, it has been also reported that ANGPTL4 prevents the metastatic process by inhibiting vascular activity as well as tumour cell motility and invasiveness $(20,21)$. The effects of ANGPTL4 in experimental systems are still unclear in tumour biology.

The objective of the present study is to evaluate the role of ANGPTL4 in the progression and differentiation of human gastric carcinoma, especially with regard to migration to vasculature and distant metastasis to other organs.

\section{Materials and methods}

Patients. We studied 103 primary human gastric adenocarcinomas: 22 mucosal carcinomas (pTis), 33 submucosal infiltrative carcinomas (pT1), 11 carcinomas invading proprial muscle layers (pT2), 15 carcinomas penetrating serosa (pT3) and 22 carcinomas invading adjacent structures (pT4). All tumour specimens were obtained from patients operated at Nagasaki University Hospital between 1998 and 2007. Each tumour was assigned a histological type according to the Japanese Classification of Gastric Carcinoma by the Japanese Research Society for Gastric Cancer (22), based on World Health Organization classification (23) and a depth grading of infiltration according to the International Union Against Cancer (UICC), TNM Classification of Malignant Tumors (24). The study had ethical approval from the Local Research Ethics Committee. The study was conducted in accordance with the Helsinki Declaration. Histologically, of the 103 primary human gastric adenocarcinomas, 5 were papillary adenocarcinomas (pap), 20 were tubular adenocarcinomas of the well-differentiated type (tub/wel), 33 were tubular adenocarcinomas of the moderately differentiated type (tub/mod), 13 were poorly differentiated adenocarcinomas of the solid type (por/solid), 11 were poorly differentiated adenocarcinomas of the non-solid type (por/non-solid), 16 were signetring cell carcinomas (sig) and 5 were mucinous adenocarcinomas (muc).

We used 10 adenomas as benign lesions with moderate dysplasia resected by endoscopic mucosal resection (EMR). Fifteen specimens of normal gastric mucosal tissue were evaluated as normal controls. The desmoplastic stromal reaction was graded according to the extent of the stromal area involved. It was defined as 'slight' (when the fibrous stromal area was $<25 \%$ of the whole tumour), 'moderate' (between 25 and 75\%) and 'extensive' (when it exceeded $75 \%$ of the whole tumour) based on the overall pattern (25). The examination was performed on routine slides to identify lymphatic and venous invasion. In addition to hematoxylin and eosin staining, we also used elastic Van Gieson staining and immunohistochemical staining for CD34 and D2-40 in all cases. Each parameter was defined as 'present' when invasion was identified with certainty, but defined as 'absent' when it was either not observed at all or not observed with certainty $(26,27)$. Lymph node metastasis was defined as 'present' only when histologically proven. Diagnosis was established by two independent pathologists (T. Nakayama and $\mathrm{T}$. Taguchi), and cases of questionable diagnosis were omitted from the study.

Among the 103 patients, 57 were used for the follow-up study. In 103 cases, 46 cases were deleted for survival analysis ( 22 cases of pTis that did not show any invasion to stroma. Three cases died within 7 days after surgery. Twenty-one cases had no data on follow-up). Forty-four patients remained disease-free for a median follow-up period of 1301 days, ranging from 150 to 3318 days. In total, 13 patients suffered from local recurrence ( 7 patients) or distant metastasis (6 patients) after the operation.

Immunohistochemistry. Formalin-fixed and paraffin-embedded tissues were cut into $4 \mu \mathrm{m}$ sections, deparaffinized in xylene, and rehydrated in phosphate-buffered saline. Deparaffinized sections were preincubated with normal rabbit serum to prevent non-specific binding, and then incubated overnight at $4^{\circ} \mathrm{C}$ with an optimal dilution $(0.1 \mu \mathrm{g} / \mathrm{ml})$ of a primary polyclonal goat antibody against human ANGPTL4 (R\&D Systems, Inc., Minneapolis, MA). The slides were sequentially incubated with a biotinylated rabbit anti-goat immunoglobulin antibody and the reaction products were viewed using diaminobenzidine (DAB; Dako Ltd., Glostrup, Denmark) and hematoxylin staining as counter staining. Primary antibody preabsorbed with excess recombinant ANGPTL4 peptides (R\&D Systems, Inc.) was used as negative controls. Human liver tissue served as the internal positive control for ANGPTL4 immunostaining (12). Analysis of the immunohistochemical staining was performed independently by two investigators ( $\mathrm{T}$. Nakayama and T. Taguchi). ANGPTL4 expression was classified into two categories depending on the percentage of cells stained: -, 0$10 \%$ positive cells;,$+>10 \%$ positive tumour cells.

Cell culture. MKN-1, MKN-28, NUGC-3 and SCH cell lines derived from human gastric cancer, were obtained from the Human Health Resources Bank (Osaka, Japan) (28). All cell lines were maintained in RPMI-1640 (Invitrogen Corp., Carlsbad, CA) supplemented with heat-inactivated $10 \%$ fetal calf serum (Invitrogen Corp.) and $2 \mathrm{mM}$ glutamine (Invitrogen Corp.), and incubated at $37^{\circ} \mathrm{C}$ in a humidified atmosphere containing $5 \% \mathrm{CO}_{2}$.

Reverse transcriptase-polymerase chain reaction (RT-PCR). Total RNA was prepared from four human gastric cancer tissues and the human gastric carcinoma cell lines MKN-1, MKN-28, NUGC-3 and SCH (28) using the acid guanidine phenol method (29). Cellular RNA $(1 \mu \mathrm{g})$ was incubated at $37^{\circ} \mathrm{C}$ for $1 \mathrm{~h}$ in $50 \mu \mathrm{l}$ of reverse transcriptase buffer containing 20 units of RNAsin (Promega Corp., Madison, WI), 100 pmol of random hexamer primers (Boehringer Mannheim, Mannheim, Germany) and 400 units of Moloney murine leukemic virus reverse transcriptase (Invitrogen Corp.). Reverse transcription was terminated by heating at $95^{\circ} \mathrm{C}$ for $10 \mathrm{~min}$ 
and $20 \%$ of the resultant cDNA was removed for PCR. PCR samples were incubated with $50 \mathrm{pmol}$ of each primer and 2.5 units of TaqDNA polymerase. The human ANGPTL4 PCR primers were 5'-GGCGAGTTCTGGCTGGGTCT-3' (sense) and 5'-TGGCCGTTGAGGTTGGAATG-3' (antisense). The human $B$-actin PCR primers were 5'-TCCTCC CTGGAGAAGACTA-3' (sense) and 5'-AGTACTTGCGC TCAGGAGGA-3' (antisense). The ANGPTL4 and B-actin primers were predicted to amplify 329 and 313 bp DNA fragments, respectively. Both primer pairs were chosen to span introns of their respective human genes. Samples were subjected to 30 cycles of PCR amplification using a thermocycler. Each cycle included denaturation at $94^{\circ} \mathrm{C}$ for $1 \mathrm{~min}$, annealing at $60^{\circ} \mathrm{C}$ for $1 \mathrm{~min}$ and primer extension at $72^{\circ} \mathrm{C}$ for $1.5 \mathrm{~min}$. An aliquot of each amplification mixture was subjected to electrophoresis on a $1.5 \%$ agarose gel and DNA was visualized by ethidium bromide staining.

Western blot analysis. Western blot analysis was performed on human gastric cancer tissues and cell lines. The tissues obtained at surgery were frozen immediately after tissue sampling. The tissues and the cells were then suspended in RIPA buffer (50 mM Tris, $150 \mathrm{mM} \mathrm{NaCl}, 1 \% \mathrm{NP}-40,1 \%$ sodium deoxycholate and $0.05 \%$ SDS, $\mathrm{pH} 7.4$ ), broken into pieces on ice, and subjected to three freeze-thaw cycles. The insoluble tissue debris was removed by centrifugation at $14000 \mathrm{x} \mathrm{g}$ at $0^{\circ} \mathrm{C}$ for $10 \mathrm{~min}$. The cell pellets were lysed in lysis RIPA buffer containing $50 \mathrm{mM}$ Tris, $150 \mathrm{mM} \mathrm{NaCl}, 1 \%$ NP-40 and $0.25 \%$ sodium deoxycholate. The cells were then cleared by centrifugation at $14000 \mathrm{x} \mathrm{g}$ at $0^{\circ} \mathrm{C}$ for $10 \mathrm{~min}$ and sample buffer was added. The supernatant was collected and the protein concentration was quantified using a protein assay reagent (Bio-Rad Laboratory, Hercules, CA). After boiling, the proteins $(20 \mu \mathrm{g})$ were separated by polyacrylamide gel electrophoresis (PAGE) under denaturing and reducing conditions, and transferred to a Hybond ECL Nitrocellulose Membrane (Amersham Pharmacia Biotech, Arlington Height, IL). The membranes were rinsed in TBS, blocked with 5\% low-fat dried milk in TBS containing 0.1\% Tween-20 (TBS-T), and then incubated for $6 \mathrm{~h}$ at room temperature with a 1:500 dilution of the anti-human ANGPTL4 antibody (R\&D Systems, Inc.). The anti-human $B$-actin antibody (Santa Cruz Biotechnology, Inc., Santa Cruz, CA) was used as an indicator for the amount of loading proteins. After extensive washing with TBS-T, the membranes were incubated for $1 \mathrm{~h}$ with a 1:1000 dilution of the horseradish-peroxidase-conjugated donkey anti-rabbit immunoglobulin G (Santa Cruz Biotechnology, Inc.) in TBS-T containing 3\% low-fat dried milk. The membranes were washed and developed with a horseradish peroxidase chemiluminescence detection reagent (ECL Plus System, Amersham Pharmacia Biotech) and then exposed to Hyperfilm ECL (Amersham Pharmacia Biotech).

Statistical analysis. The Stat View II Program (Abacus Concepts, Inc., Berkeley, CA) was used for statistical analyses. Analyses comparing the expression of ANGPTL4 were performed by the $\chi^{2}$ test for independence or Fisher's exact probability test, the Mann-Whitney's U test. Survival durations were calculated using the Kaplan-Meier method. A log-rank test was used to calculate the significance of dif-
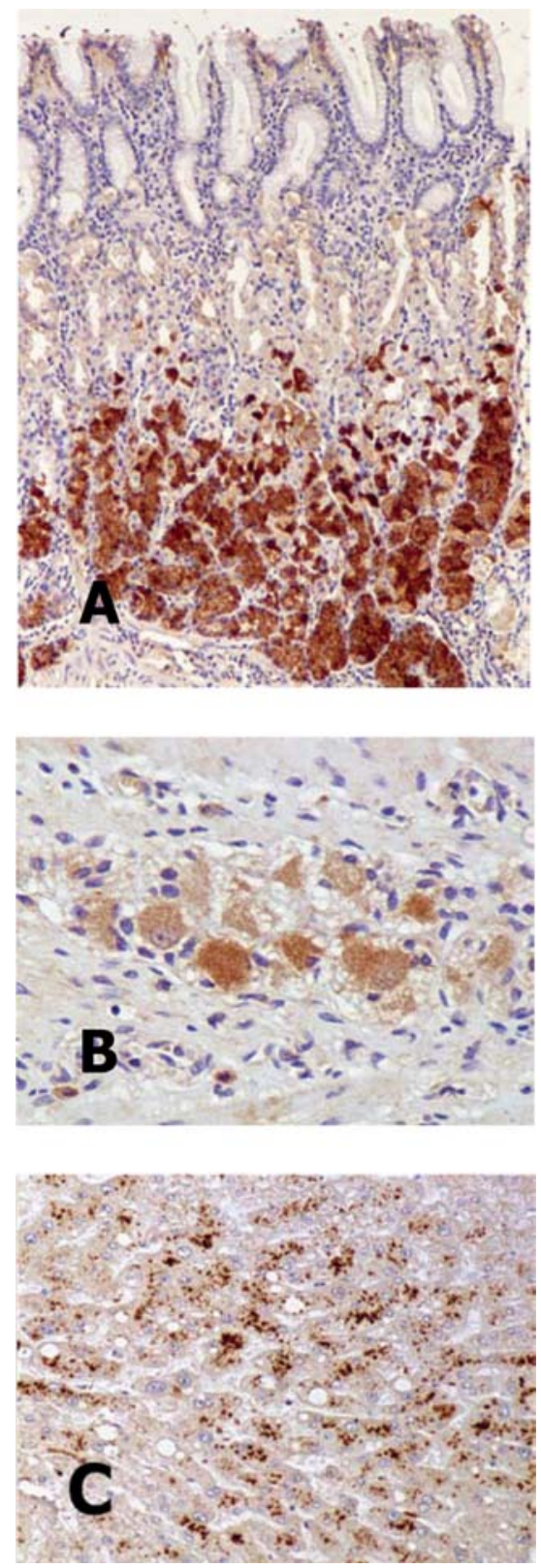

Figure 1. Immunohistochemical staining for ANGPTL4 in human gastric tissue. ANGPTL4 is expressed in cytoplasm of the chief cells of fundic gland (A) and neural cell of myenteric plexus (B). Human liver tissue is shown as positive control for immunostaining (C). [Magnification: x20 (A), x100 (B), x100 (C)].

ferences in the survival analysis. A probability level of $<0.05$ was considered to indicate a significant difference.

\section{Results}

The expression of ANGPTL4 in normal gastric tissue detected by immunohistochemical staining. In normal gastric tissue, ANGPTL4 was expressed in the chief cells of fundic gland and was not expressed in the cells of pyloric gland, the surface lining cells with mucin production, nor the mucosa with intestinal metaplasia (Fig. 1A). Further, ANGPTL4 was also expressed faintly in neural cells in submucosal and myenteric plexus (Fig. 1B). Human liver tissue served as the internal positive control for ANGPTL4 immunostaining (Fig. 1C). 
Table I. The expression of ANGPTL4 and clinicopathological factors.

\begin{tabular}{|c|c|c|c|c|}
\hline & $\mathrm{n}$ & + & - & \\
\hline Tubular adenoma & 10 & $1(10.0)$ & $9(90.0)$ & \\
\hline Total carcinoma & 103 & $38(36.9)$ & $65(63.1)$ & \\
\hline \multicolumn{5}{|c|}{ Histological differentiation } \\
\hline i) Papillary & 5 & $3(60.0)$ & $2(40.0)$ & n.s. \\
\hline Tubular/well & 20 & $8(40.0)$ & $12(60.0)$ & \\
\hline Tubular/mod & 33 & $12(36.4)$ & $21(63.6)$ & \\
\hline Poor/solid & 13 & $6(46.2)$ & $7(53.8)$ & \\
\hline Poor/non-solid & 11 & $4(36.4)$ & $7(63.8)$ & \\
\hline Signet-ring cell & 16 & $2(12.5)$ & $14(87.5)$ & \\
\hline Mucinous & 5 & $3(60.0)$ & $2(40.0)$ & \\
\hline ii)Intestinal type & 58 & $23(39.7)$ & $35(60.3)$ & n.s. \\
\hline Diffuse type & 45 & $15(33.3)$ & $30(66.7)$ & \\
\hline \multicolumn{5}{|c|}{ Depth of tumour invasion } \\
\hline pTis & 22 & $4(18.2)$ & $18(81.8)$ & $\mathrm{p}<0.005^{\mathrm{a}}$ \\
\hline pT1 & 33 & $9(27.3)$ & $24(72.7)$ & \\
\hline pT2 & 26 & $13(50.0)$ & $13(50.0)$ & \\
\hline pT3 & 21 & $12(57.1)$ & $9(42.9)$ & \\
\hline pT4 & 1 & $0 \quad(0.0)$ & $1(100)$ & \\
\hline \multicolumn{5}{|c|}{ Lymph node metastasis } \\
\hline Present & 29 & $18(62.1)$ & $11(37.9)$ & $\mathrm{p}<0.001^{\mathrm{b}}$ \\
\hline Absent & 74 & $20(27.0)$ & $54(73.0)$ & \\
\hline \multicolumn{5}{|l|}{ Lymph duct invasion } \\
\hline Present & 64 & $30(46.9)$ & $34(53.1)$ & $\mathrm{p}<0.01^{\mathrm{b}}$ \\
\hline Absent & 39 & $8(20.5)$ & $31(79.5)$ & \\
\hline \multicolumn{5}{|l|}{ Venous invasion } \\
\hline Present & 47 & $28(59.6)$ & $19(40.4)$ & $\mathrm{p}<0.00005^{\mathrm{b}}$ \\
\hline Absent & 56 & $10(17.9)$ & $46(82.1)$ & \\
\hline \multicolumn{5}{|l|}{ TNM-stage } \\
\hline 0 & 22 & $4(18.2)$ & $18(81.8)$ & $\mathrm{p}<0.001^{\mathrm{a}}$ \\
\hline $1 \mathrm{a}$ & 32 & $9(28.1)$ & $23(71.9)$ & \\
\hline $1 b$ & 17 & $6(35.3)$ & $11(64.7)$ & \\
\hline 2 & 8 & $3(37.5)$ & $5(62.5)$ & \\
\hline $3 a$ & 13 & $9(69.2)$ & $4(30.8)$ & \\
\hline $3 b$ & 6 & $5(83.3)$ & $1(16.7)$ & \\
\hline 4 & 5 & $2(40.0)$ & $3(60.0)$ & \\
\hline
\end{tabular}

n.s., not significant. ${ }^{a}$ Mann-Whitney's $U$ test; ${ }^{b} \chi^{2}$ for independence test.

Immunohistochemical analyses of clinicopathological factors. We have summarized the immunohistochemical results in Tables I and II. Only one of ten adenomas cases with moderate dysplasia resected by endoscopic mucosal resection (EMR) had positive staining for ANGPTL4 (Table I). Among 103 cases of adenocarcinoma, 38 cases (36.9\%) showed positive staining for ANGPTL4 in the cytoplasm of carcinoma cells (Fig. 2). Also, the invasive component of the primary tumour was more intensely stained than the superficial part of the tumour in almost all cases of invasive carcinoma.

Histologically, papillary adenocarcinoma showed relatively high expression of ANGPTL4 (60\%) (Table I). However, only two cases $(12.5 \%)$ of 16 signet-ring cell carcinomas showed positive staining for ANGPTL4. The expression of ANGPTL4 was not correlated with the degree of histological differentiation. 
Table II. Tumour invasive pattern and ANGPTL4 expression in invasive cancer (86 cases).

\begin{tabular}{lccc}
\hline & $\mathrm{n}$ & + & - \\
P-value \\
\hline $\begin{array}{l}\text { Invasive cancer } \\
\text { Desmoplastic stromal reaction }\end{array}$ & 86 & $36(41.9)$ & $50(58.1)$ \\
$\quad$ Slight & 15 & $10(66.7)$ & $5(33.3)$ \\
$\quad$ Moderate & 44 & $19(43.2)$ & $25(56.8)$ \\
$\quad$ Extensive & 27 & $7(25.9)$ & $20(74.1)$ \\
Tumour growth pattern & & & $6(35.3)$ \\
$\quad$ Solid & 17 & $11(64.7)$ & $21(60.0)$ \\
$\quad$ Intermediate & 35 & $14(40.0)$ & $23(67.6)$ \\
$\quad$ Diffuse & 34 & $11(32.4)$ & $<0.05^{\mathrm{a}}$
\end{tabular}

a⿳Mann-Whitney's U test.
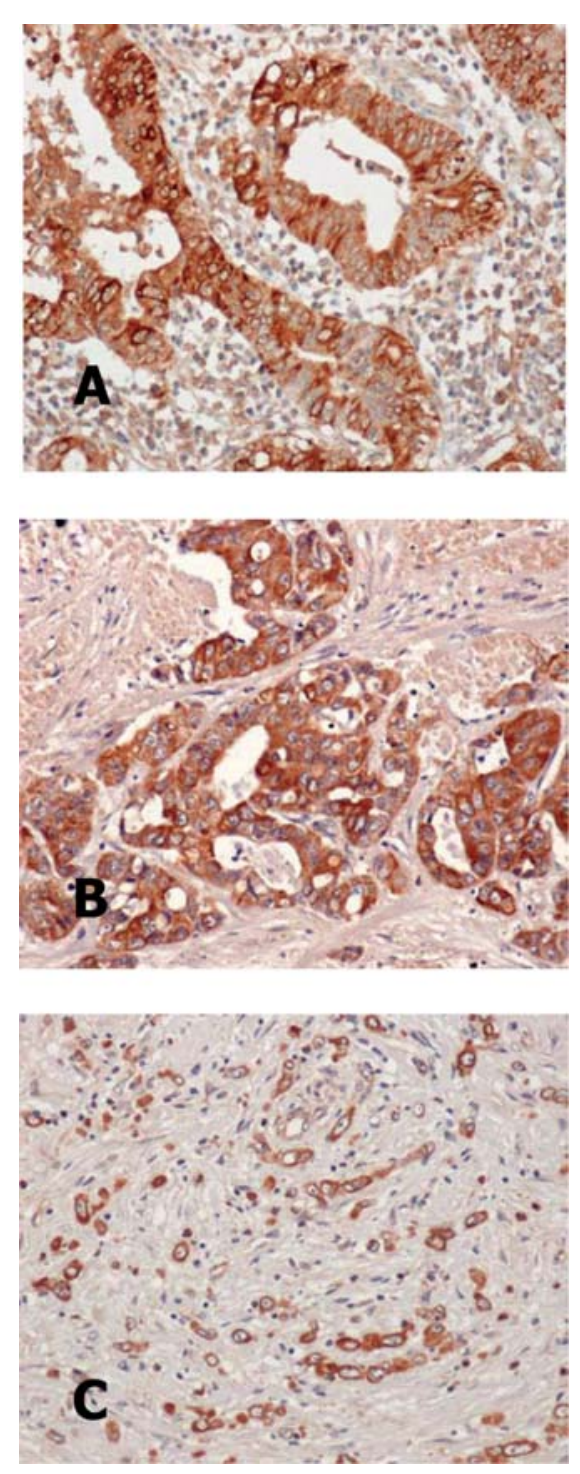

Figure 2. Immunohistochemical staining for ANGPTL4 in human gastric cancer. Positive staining for ANGPTL4 in cytoplasm of human gastric cancer. (A) Well-differentiated adenocarcinoma, (B) moderately-differentiated adenocarcinoma and $(\mathrm{C})$ poorly-differentiated adenocarcinoma (non-solid type) of human gastric cancer. [Magnification: x100 (A), x100 (B) and x100 (C)].

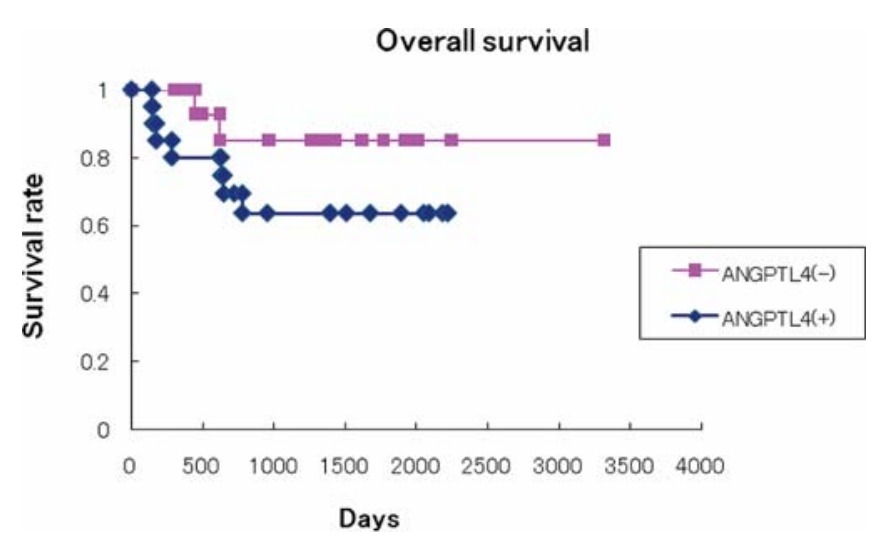

Figure 3. Overall survival based on the expression of ANGPTL4 in human gastric cancer (57 cases). ANGPTL4 expression was not associated with the overall survival in univariate survival analysis ( $\mathrm{p}=0.086$ in log-rank test).

The degree of immunoreactivity appears to be correlated with the degree of tumour invasion (Table I). Statistical analysis showed significant correlation with the TNM staging $(\mathrm{p}<0.001)$. Further, ANGPTL4 expression was correlated with the presence of lymph node metastasis $(p<0.001)$ and lymph duct invasion $(\mathrm{p}<0.01)$ in the total carcinoma. In particular, the expression of ANGPTL4 was significantly correlated with venous invasion $(\mathrm{p}<0.00005)$. In 86 cases of invasive carcinoma, ANGPTL4 expression was correlated with the desmoplastic stromal reaction $(\mathrm{p}<0.05)$, and with the tumour growth pattern $(\mathrm{p}<0.05)$ (Table II).

Overall survival analysis and prognosis after surgery. We analyzed overall survival in 57 patients with invasive carcinoma based on their expression of ANGPTL4 in human gastric cancer. However, ANGPTL4 expression was not associated with the overall survival by Kaplan-Meier method ( $\mathrm{p}=0.086$ in log-rank test) (Fig. 3).

ANGPTL4 immunoreactivity was compared with the prognosis after surgery in 57 patients that were also analyzed for overall survival (Table III). ANGPTL4 expression was found in $43.2 \%(19 / 44)$ of disease-free and in $46.2 \%(6 / 13)$ 
A

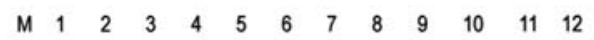

\section{ANGPTL4}

$\beta$-actin

\section{B}

ANGPTL4

$\beta$-actin

Figure 4. RT-PCR for ANGPTL4 in human gastric cancer: tissues and cell lines (A). M, 100 bp ladder marker (Invitrogen, Inc.). The expression of ANGPTL4 in human gastric cancer tissues and cultured cell lines by Western blotting (B). Human gastric cancer tissues (1-8) and human gastric cancer cell lines (9-12). (1, normal gastric tissue, Case-1; 2, cancer tissue, Case-1; 3, normal gastric tissue, Case-2; 4, cancer tissue, Case-2; 5, normal gastric tissue, Case-3; 6, cancer tissue, Case-3; 7, normal gastric tissue Case-4; 8, cancer tissue, Case-4; 9, MKN-1; 10, MKN-28; 11, NUGC-3; 12 , $\mathrm{SCH})$.

of recurrence or metastasis cases and the expression of ANGPTL4 was not significantly different between diseasefree and the sum of local recurrence and distant metastasis cases. Moreover, among 13 patients with local recurrence or distant metastasis, 7 patients $(53.8 \%)$ were locally recurred (Table III). Noteworthily, all these cases with local recurrence were negative for ANGPTL4, while the remaining 6 patients $(46.2 \%, 6 / 13)$ suffered distant metastasis to other organs: 2 of lung, 2 of liver, 1 of brain and 1 of spinal cord. These cases all showed positive staining for ANGPTL4. The expression of ANGPTL4 was statistically correlated with the presence of distant metastasis to other organs $(\mathrm{p}<0.001)$.

RT-PCR and Western blotting for ANGPTL4 in human gastric tissues and cultured cell lines. RT-PCR showed mRNA expression of ANGPTL4 and Western blot analysis showed intense expression of ANGPTL4 protein in all 8 surgicallyresected samples, 4 normal mucosas, 4 invasive carcinomas and all four cultured cell lines of human gastric adenocarcinoma (Fig. 4A and B, respectively). Expression of ANGPTL4 protein in invasive carcinoma was more intense than in normal mucosa in every case (Fig. 4B).

\section{Discussion}

The tumour microenvironment plays an important role in molecular mechanism of metastasis (30). Primary carcinomas, as well as metastases, are comprised of both tumour cells and cells of the stroma including fibroblasts, endothelial cells, and inflammatory cells. The cytokine TGF- $\beta$ is produced by stromal cells of the tumour microenvironment in response to hypoxia or inflammation or by carcinoma-associated fibroblasts (31). Recently, Padua et al showed that TGF- 3 stimulates expression of the adipokine ANGPTL4 by activating SMAD transcription factors (19). Tumour cell-derived ANGPTL4 disrupts vascular endothelial cell-cell junctions, increases the permeability of capillaries, and facilitates the trans-endothelial passage of tumour cells. Secretion of ANGPTL4 enables tumour cells to extravasate into other tissue and to seed micrometastases. ANGPTL4 contains an amino-terminal coiled-coil domain and a carboxyl-terminal fibrinogen-like domain. Oligomerized ANGPTL4 undergoes proteolytic processing to release its carboxyl fibrinogen-like domain, which circulates in serum (14). In this study, the expression of ANGPTL4 protein in tissues from all 4 cases of invasive carcinomas was more intense than normal tissue (Fig. 4B). ANGPTL4 may promote the vascular invasion and the distant metastasis in human gastric cancer through the activation of fibrinogen-like domein of ANGPTL4.

The angiopoietin family of growth factors has recently been identified as ligands for Tie-2. Angiopoietin (Ang)-1 activates Tie-2 leading to receptor autophosphorylation upon binding and also stimulates endothelial cell migration in vitro $(32,33)$. Ang-2 appears to be a natural inhibitor of Tie-2 function, binding to Tie-2 with an affinity similar to that of Ang-1 and blocks Ang-1-stimulated receptor phosphorylation in endothelial cells $(33,34)$. Deletion of the Ang-1 gene or overexpression of Ang-2 in transgenic mice results in death in utero due to a widespread failure of microvascular morphogenesis similar to that observed in Tie-2 knock-out mice (34-36). Ang-3 and Ang-4 are more recently described members of this family that seem to represent the mouse and human counterparts of the same genetic locus (37). Ang-4 seems to act as an agonist for the Tie- 2 receptor and is expressed at high levels in lung (37). However, in contrast to other proteins of the angiopoietin family, ANGPTL4 does not bind the Tie- 2 receptor and the receptor for ANGPTL4 is still unknown. The role of the ANGPTL4 has not been fully clarified in cancer biology, particularly the relationship between the expression of ANGPTL4 and the clinicopathological features of human cancer.

There are few reports on ANGPTL4 protein or gene expression profile in cell lines of breast cancer $(19,38)$, lung

Table III. The cause of death in follow-up patients and the expression of ANGPTL4 (57 cases).

\begin{tabular}{|c|c|c|c|c|}
\hline & $\mathrm{n}$ & + & - & \\
\hline Total cases & 57 & $25(43.9)$ & $32(56.1)$ & \\
\hline Disease-free & 44 & $19(43.2)$ & $25(56.8)$ & n.s. \\
\hline Recurrence or distant metastasis & 13 & $6(46.2)$ & $7(53.8)$ & \\
\hline Local recurrence & 7 & $0 \quad(0.0)$ & $7(100)$ & $\mathrm{p}<0.001^{\mathrm{a}}$ \\
\hline Distant metastasis & 6 & $6(100)$ & $0 \quad(0.0)$ & \\
\hline
\end{tabular}

n.s., not significant. ${ }^{a}$ Fisher's exact probability test. 
cancer (20), hepatocellular carcinoma (39), prostate cancer (40) and melanoma (21). Angiopoietin family members usually regulate the differentiation or invasion of cancer cells through the activation of its receptor Tie- 2 and downstream tyrosine kinase pathway $(8,9,41)$. However, ANGPTL4 does not bind to Tie- 2 but contains motifs structurally conserved in angiopoietins. In this study, we investigated the expression of ANGPTL4 in human gastric cancer using immunohistochemical and molecular biological techniques. This is the first investigation of the role of ANGPTL4 in human gastric cancer.

In cancer research, tumour progression, local invasion and tumour metastases determine the prognosis of cancer patients. Although the cellular mechanisms of metastasis affect the different tumour cell properties $(42,43)$, the important initial step of cancer metastasis is the invasion into the capillary and/or lymph duct through the tight endothelial junctions. Some factors, such as growth factors and cytokines derived from cancer cell, change the vascular permeability $(44,45)$. Statistical analyses of our data showed a correlation between ANGPTL4 expression and venous invasion, lymph duct invasion, and metastasis to lymph nodes (Table I). The cancer cells with venous invasion showed strong immunopositivity for ANGPTL4 proteins in the cytoplasm of carcinoma cells. One report have described that ANGPTL4 upregulates the infiltration into the capillary adjacent to the tumour due to acute disruptions of the endothelial cell-cell junctions caused by ANGPTL4 (19). Further, the strong interaction of ANGPTL4 with the subendothelial extracellular matrix (ECM) is heparin/heparan sulfate proteoglycandependent (46). The balance between matrix-associated and soluble forms of ANGPTL4 points to the role of the ECM in the regulation of its bioavailability (46). Our study strongly supports the previous report that ANGPTL4 promotes the capillary and/or lymph duct invasion as the first step of cancer metastasis.

Tumour desmoplasia is a common feature in several malignant human tumours and it has been reported that a poorly defined tumour border at the invasive tumour edge is associated with a poorer prognosis in colorectal cancer (47). Carcinoma cell/stromal cell interaction is important for the processes of carcinoma invasion and metastasis (48). However, there was no report of the relationship between the stromal reaction and the expression of ANGPTL4 in cancer. In this study, although many cases of gastric carcinoma expressed ANGPTL4 in the cytoplasm of malignant cells, fibrous stromal cells did not show any expression of ANGPTL4 (data not shown). Moreover, the expression of ANGPTL4 in carcinoma cells was significantly inversely correlated with the extent of fibrous stromal tissue. Our results suggest that the expression of ANGPTL4 protein has potential as one of many prognostic factors in gastric cancer.

ANGPTL4 expression was not associated with the overall survival by log-rank test (Fig. 3). However, survival rate was relatively better in the patients without expression of ANGPTL4. In this study, only 57 cases were investigated and included many cases with short-term follow-up. Further investigation for the detailed prognostic evaluation using substantially more cases is warranted. The expression of ANGPTL4 correlates with venous invasion, which may lead to distant metastasis to other organs through blood flow (19). In this study, the cause of death in 6 of the follow-up cases was distant metastasis to other organs, such as liver, lung, or brain (Table III). Further, all 6 cases with distant metastases were positive for ANGPTL4. We hypothesized worse survival outcome of the patients with ANGPTL4 due to the high incidence of distant metastasis. However, there was no statistical difference in overall survival of patients with or without ANGPTL4. Prognostic investigation showed specifically that 7 cases without ANGPTL4 in 13 patients of cancer related-death showed local recurrence (Table III). Some reports indicated that ANGPTL4 regulates the cell motility and invasiveness $(20,21)$. These findings suggest that the carcinoma with ANGPTL4 is more susceptible to distant metastasis and the carcinoma without ANGPTL4 shows a tendency for stromal invasion. The examination of ANGPTL4 in carcinoma tissue may predict the incidence of distant metastasis in human gastric cancer. However, only 57 cases were investigated for follow-up in this study. Further investigation for the detailed prognostic evaluation is needed.

ANGPTL4 was expressed in human gastric adenocarcinoma and was correlated with several clinicopathological factors, especially venous invasion and distant metastasis. These findings suggest that ANGPTL4 is one of the factors involved in the progression of human gastric cancer. However, the detailed mechanisms of ANGPTL4 protein in human gastric cancer requires further investigation.

\section{Acknowledgements}

This study was supported in part by a grant from Nagasaki University. We are grateful to Mr. Toshiyuki Kawada (Nagasaki University Graduate School of Biomedical Sciences) for his excellent immunohistochemical and molecular biological assistance.

\section{References}

1. Neugut AI, Hayek M and Howe G: Epidemiology of gastric cancer. Semin Oncol 23: 281-291, 1996.

2. Vogelstein B, Fearon ER, Hamilton SR, Kern SE, Preisinger AC, Leppert M, Nakamura Y, White R, Smits AM and Bos JL: Genetic alterations during colorectal-tumor development. New Engl J Med 319: 525-532, 1988.

3. Ming SC: Pathology of the gastrointestinal tract. 2nd edition. Ming SC and Goldman H (eds). Williams \& Wilkins, Baltimore, pp632-633, 1998.

4. Goseki N, Koike M and Yoshida M: Histopathologic characteristics of early stage esophageal carcinoma. A comparative study with gastric carcinoma. Cancer 69: 1088-1093, 1992.

5. Fidler IJ: Critical determinants of cancer metastasis: rationale for therapy. Cancer Chemother Pharmacol 43 (Suppl.): S3-S10, 1999.

6. Fidler IJ: Critical determinants of human colon cancer metastasis. In: Molecular Pathology of Gastroenterological Cancer. Tahara E (ed). Springer-Verlag, Berlin, pp147-169, 1997.

7. Yasui W, Oue N, Aung PP, Matsumura S, Shutoh M and Nakayama H: Molecular-pathological prognostic factors of gastric cancer. Gastric Cancer 8: 86-94, 2005.

8. Nakayama T, Hatachi G, Wen CY, Yoshizaki A, Yamazumi K, Niino D and Sekine I: Expression and significance of Tie-1 and Tie-2 receptors, and angiopoietins-1,2 and 4 in colorectal adenocarcinoma: immunohistochemical analysis and correlation with clinicopathological factors. World J Gastroenterol 11: 964-969, 2005. 
9. Nakayama T, Yoshizaki A, Kawahara N, Ohtsuru A, Wen CY, Fukuda E, Nakashima M and Sekine I: Expression of Tie-1 and 2 receptors, and angiopoietin-1, 2 and 4 in gastric carcinoma; immunohistochemical analyses and correlation with clinicopathological factors. Histopathology 44: 232-239, 2004.

10. Bach F, Uddin FJ and Burke D: Angiopoietins in malignancy. Eur J Surg Oncol 33: 7-15, 2007.

11. Yu X, Burgess SC, Ge H, Wong KK, Wong KK, Nassem RH, Garry DJ, Sherry AD, Malloy CR, Berger JP and Li C: Inhibition of cardiac lipoprotein utilization by transgenic overexpression of ANGPTL4 in the heart. Proc Natl Acad Sci USA 102 $1767-1772,2005$

12. Mandard S, Zandbergen F, van Straten E, Wahli W, Kuipers F, Müller M and Kersten S: The fasting-induced adipose factor/ angiopoietin-like protein 4 is physically associated with lipoproteins and governs plasma lipid levels and adiposity. J Biol Chem 281: 934-944, 2006.

13. Romeo S, Pennacchio LA, Fu Y, Boerwinkle E, TybjaergHansen A, Hobbs $\mathrm{HH}$ and Cohen JC: Population-based resequencing of ANGPTL4 uncovers variations that reduce triglycerides and increase HDL. Nat Genet 39: 513-516, 2007.

14. Ge H, Yang G, Huang L, Motola DL, Pourbahrami T and Li C: Oligomerization and regulated proteolytic processing of angiopoietin-like protein 4. J Biol Chem 279: 2038-2045, 2004.

15. Le Jan S, Amy C, Cazes A, Monnot C, Lamandé N, Favier J, Philippe J, Sibony M, Gasc JM, Corvol P and Germain S: Angiopoietin-like 4 is a proangiogenic factor produced during ischemia and in conventional renal cell carcinoma. Am J Pathol 162: 1521-1528, 2003

16. Yoshida K, Shimizugawa T, Ono M and Furukawa H: Angiopoietin-like protein 4 is a potent hyperlipidemia-inducing factor in mice and inhibitor of lipoprotein lipase. J Lipid Res 43: 1770-1772, 2002.

17. Xu A, Lam MC, Chan KW, Wang Y, Zhang J, Hoo RL, Xu JY, Chen B, Chow WS, Tso AW and Lam KS: Angiopoietin-like protein 4 decreases blood glucose and improves glucose tolerance but induces hyperlipidemia and hepatic steatosis in mice. Proc Natl Acad Sci USA 102: 6086-6091, 2005.

18. Oike Y, Yasunaga K and Suda T: Angiopoietin-related/ angiopoietin-like proteins regulate angiogenesis. Int J Hematol 80: 21-28, 2004

19. Padua D, Zhang XH, Wang Q, Nadal C, Gerald WL, Gomis RR and Massagué J: TGFbeta primes breast tumors for lung metastasis seeding through angiopoietin-like 4. Cell 133: 66-77, 2008.

20. Galaup A, Cazes A, Le Jan S, Philippe J, Connault E, Le Coz E, Mekid H, Mir LM, Opolon P, Corvol P, Monnot C and Germain S: Angiopoietin-like 4 prevents metastasis through inhibition of vascular permeability and tumor cell motility and invasiveness. Proc Natl Acad Sci USA 103: 18721-18726, 2006.

21. Girroir EE, Hollingshead HE, Billin AN, Willson TM, Robertson GP, Sharma AK, Amin S, Gonzalez FJ and Peters JM: Peroxisome proliferator-activated receptor-beta/delta (PPARbeta/ delta) ligands inhibit growth of UACC903 and MCF7 human cancer cell lines. Toxicology 243: 236-243, 2008.

22. Japanese Research Society for Gastric Cancer: Japanese classification of gastric cancer. Kanehara Press, Tokyo, 1995.

23. Watanabe H, Jass JR and Sabin LH: Histological typing of oesophageal and gastric tumors. World Health Organization International Histological Classification of Tumors. Springer, Berlin, pp20-26, 1989.

24. Sobin LH and Wittekind $\mathrm{CH}$ (eds): International Union Against Cancer. TNM classification of malignant tumors. 5th edition. John Wiley \& Sons, Inc., New York, 1997.

25. Jass JR, Atkin WS, Cuzick J, Bussey HJ, Morson BC, Northover JM and Todd IP: The grading of rectal cancer: histological perspective and a multivariate analysis of 447 cases. Histopathology 10: 437-459, 1986.

26. Seefeld PH and Bargen JA: The spread of cancer of the rectum invasion of the lymphatics, veins and nerves. Ann Surg 118: 76-89, 1943

27. Talbot IC, Ritchie S, Leighton M, Hughes AO, Bussey HJ and Morson BC: Invasion of veins by carcinoma of rectum: methods of detection, histological features and significance. Histopathology 5: 141-163, 1981 .

28. Nakayama T, Yoshizaki A, Izumida S, Suehiro T, Miura S, Uemura T, Yakata Y, Shichijo K, Yamashita S and Sekin I: Expression of interleukin-11 (IL-11) and IL-11 receptor alpha in human gastric carcinoma and IL-11 upregulates the invasive activity of human gastric carcinoma cells. Int J Oncol 30: $825-833,2007$
29. Van Dekken H, Pizzolo JG, Kelsen DP and Melamed MR Targeted cytogenetic analysis of gastric tumors by in situ hybridization with a set of chromosome-specific DNA probes. Cancer 66: 491-497, 1990.

30. McSherry EA, Donatello S, Hopkins AM and McDonnell S: Molecular basis of invasion in breast cancer. Cell Mol Life Sci 64: 3201-3218, 2007

31. Bierie B and Moses HL: Tumour microenvironment: TGFbeta the molecular Jekyll and Hyde of cancer. Nat Rev Cancer 6: 506-520, 2006

32. Davis S, Aldrich TH, Jones PF, Acheson A, Compton DL, Jain V, Ryan TE, Bruno J, Radziejewski C, Maisonpierre PC and Yancopoulos GD: Isolation of angiopoietin-1, a ligand for the Tie2 receptor, by secretion-trap expression cloning. Cell 87: 1161-1169, 1996

33. Witzenbichler B, Maisonpierre PC, Jones P, Yancopoulos GD and Isner $\mathrm{J}$ : Chemotactic properties of angiopoietin-1 and -2 , ligands for the endothelial-specific receptor tyrosine kinase Tie2. J Biol Chem 273: 18514-18521, 1998.

34. Maisonpierre PC, Suri C, Jones PF, Bartunkova S, Wiegand SJ, Radziejewski C, Compton D, McClain J, Aldrich TH, Papadopoulos N, Daly TJ, Davis S, Sato TN and Yancopoulos GD: Angiopoietin-2, a natural antagonist for Tie2 that disrupts in vivo angiogenesis. Science 277: 55-60, 1997.

35. Suri C, Jones PF, Patan S, Bartunkova S, Maisonpierre PC, Davis S, Sato TN and Yancopoulos GD: Requisite role of angiopoietin-1, a ligand for the TIE2 receptor, during embryonic angiogenesis. Cell 87: 1171-1180, 1996.

36. Sato TN, Tozawa Y, Deutsch U, Wolburg-Buchholz K, Fujiwara Y, Gendron-Maguire M, Gridley T, Wolburg H, Risau W and Qin Y: Distinct roles of the receptor tyrosine kinases Tie-1 and Tie-2 in blood vessel formation. Nature 376 : 70-74, 1995.

37. Valenzuela DM, Griffiths JA, Rojas J, Aldrich TH, Jones PF, Zhou H, McClain J, Copeland NG, Gilbert DJ, Jenkins NA, Huang T, Papadopoulos N, Maisonpierre PC, Davis S and Yancopoulos GD: Angiopoietins 3 and 4: diverging gene counterparts in mice and humans. Proc Natl Acad Sci USA 96: 1904-1909, 1999

38. Kawai Y, Minami T, Fujimori M, Hosaka K, Mizuno R, Ikomi F, Kodama $\mathrm{T}$ and Ohhashi T: Characterization and microarray analysis of genes in human lymphatic endothelial cells from patients with breast cancer. Lymphat Res Biol 5: 115-126, 2007.

39. Li KQ, Li WL, Peng SY, Shi XY, Tang HL and Liu YB: Antitumor effect of recombinant retroviral vector-mediated human ANGPTL4 gene transfection. Chin Med J (Engl) 117: 1364-1369, 2004.

40. Ifon ET, Pang AL, Johnson W, Cashman K, Zimmerman S, Muralidhar S, Chan WY, Casey J and Rosenthal LJ: U94 alters FN1 and ANGPTL4 gene expression and inhibits tumorigenesis of prostate cancer cell line PC3. Cancer Cell Int 5: 19, 2005.

41. Lewis CE, De Palma M and Naldini L: Tie2-expressing monocytes and tumor angiogenesis: regulation by hypoxia and angiopoietin-2. Cancer Res 67: 8429-8432, 2007.

42. Crissman JD, Hatfield JS, Menter DG, Sloane B and Honn KV: Morphological study of the interaction of intravascular tumor cells with endothelial cells and subendothelial matrix. Cancer Res 48: 4065-4072, 1988.

43. Hynes RO: Integrins: bidirectional, allosteric signaling machines. Cell 110: 673-687, 2002

44. Carmeliet P: Angiogenesis in health and disease. Nat Med 9: 653-660, 2003.

45. Achen MG, McColl BK and Stacker SA: Focus on lymphangiogenesis in tumor metastasis. Cancer Cell 7: 121-127, 2005.

46. Cazes A, Galaup A, Chomel C, Bignon M, Bréchot N, Le Jan S, Weber H, Corvol P, Muller L, Germain S and Monnot C: Extracellular matrix-bound angiopoietin-like 4 inhibits endothelial cell adhesion, migration and sprouting and alters actin cytoskeleton. Circ Res 99: 1207-1215, 2006.

47. Halvorsen TB and Seim E: Association between invasiveness, inflammatory reaction, desmoplasia and survival in colorectal cancer. J Clin Pathol 42: 162-166, 1989.

48. Shiozawa J, Ito M, Nakayama T, Nakashima M, Kohno S and Sekine I: Expression of matrix metalloproteinase-1 in human colorectal carcinoma. Mod Pathol 13: 925-933, 2000. 